\title{
Catalogue of the type material of Phlebotominae (Diptera, Psychodidae) deposited in the Instituto Evandro Chagas, Brazil
}

\author{
Thiago Vasconcelos dos Santos', Maria Sueli Barros Pinheiro', \\ Andrey José de Andrade ${ }^{2,3}$
}

I Laboratório de Leishmanioses Prof. Dr. Ralph Lainson, Instituto Evandro Chagas, Secretaria de Vigilância em Saúde, Ministério da Saúde. Rod. BR 316, Km 07 s/n. 67030-000, Levilândia, Ananindeua, PA, Brazil 2 Departamento de Epidemiologia, Faculdade de Saúde Pública, Universidade de São Paulo, Avenida Doutor Arnaldo 715, 01246-904, São Paulo, SP, Brazil 3 Laboratório de Parasitologia e Biologia de Vetores, Area de Patologia, Faculdade de Medicina, Universidade de Brasilia, Campus Universitário Darcy Ribeiro, Asa Norte, 70910-900, Distrito Federal, Brazil

Corresponding author: Thiago Vasconcelos dos Santos (thiagovasconcelos@iec.pa.gov.br)

Academic editor: X. Mengual | Received 10 October 2013 | Accepted 12 March 2014 | Published 1 April 2014

Citation: Santos TV, Pinheiro MSB, Andrade AJ (2014) Catalogue of the type material of Phlebotominae (Diptera, Psychodidae) deposited in the Instituto Evandro Chagas, Brazil. ZooKeys 395: 11-21. doi: 10.3897/zookeys.395.6417

\begin{abstract}
The available type material of Phlebotominae (Diptera, Psychodidae) deposited in the "Coleção de Flebotomíneos" of the Instituto Evandro Chagas (ColFleb IEC) is now presented in an annotated catalogue comprising a total of 121 type specimens belonging to 12 species as follow: Nyssomyia richardwardi (2 female paratypes), Nyssomyia shawi (9 male and 25 female paratypes), Nyssomyia umbratilis (female holotype and 1 female paratype), Nyssomyia yuilli yuilli (1 male and 1 female paratypes), Pintomyia gruta (1 male and 2 female paratypes), Psychodopygus lainsoni (2 male syntypes), Psychodopygus leonidasdeanei (male holotype, female "allotype" and 45 female paratypes), Psychodopygus llanosmartinsi (2 female paratypes), Psychodopygus wellcomei (1 male and 4 female "syntypes"), Trichophoromyia readyi (male holotype, female "allotype" and 1 male paratype), Trichophoromyia adelsonsouzai (male holotype, 13 male 5 female paratypes), and Trichophoromyia brachipyga (1 male paratype).
\end{abstract}

\section{Keywords}

Collection, sand flies, taxonomy, leishmaniasis

Copyright Thiago V. dos Santos et al. This is an open access article distributed under the terms of the Creative Commons Attribution License (CC BY 4.0), which permits unrestricted use, distribution, and reproduction in any medium, provided the original author and source are credited. 


\section{Introduction}

In the Americas, more than 450 species of the subfamily Phlebotominae Rondani, 1840 (Diptera: Psychodidae) have been described (Galati 2003) and 267 of these have so far been recorded in Brazil (Andrade et al. 2013). Phlebotomine sand flies play an important role in the transmission of virus, bacteria and protozoa, mainly Leishmania species. In Brazil six and eleven species have been incriminated or suspected, respectively, in the epidemiology of cutaneous leishmaniasis (Ready 2013). On the other hand and also in Brazil, the main vector of visceral leishmaniasis is the psychodid Lutzomyia longipalpis (Lutz \& Neiva, 1912) while L. cruzi (Mangabeira, 1942) and L. almerioi Galati \& Nunes, 1999 have been indicated as suspected vectors (Santos et al. 1998, Savani et al. 2009).

Biological collections are an important source of information on the composition, distribution and biological degree of biodiversity (Suarez and Tsutsui 2004). In addition, the types (the specimens described in the first published account of a new taxonomic group) deposited in these collections are the most valuable material for this information and their maintenance thus depends on financial support and curatorial care (NPS 2005).

In Brazil, there are six depositary institutions with type-species of sand flies. One of these is the "Coleção de Flebotomíneos" in the Instituto Evandro Chagas (IEC), known by the acronym "ColFleb IEC", located in Ananindeua municipality, State of Pará. At present, this collection consists of approximately 140 taxa distributed in species and subspecies levels of Phlebotominae (Fraiha and Ryan 1986). Most of them were collected, mounted and deposited by previous researchers in the IEC during studies on the ecology and epidemiology of leishmaniasis in Amazonian Brazil (Lainson and Shaw 2005).

Some glass slide labels of non-type material revealed that the oldest specimens of this collection belong to the 1960's (TVS, personal observation). Although a total of 55 valid species have been described by researchers directly related to the Instituto Evandro Chagas between 1945 and 2014 (Fraiha and Ryan 1986, Santos et al. 2014), some of these type specimens seem to have been lost, such as Evandromyia carmelinoi (Ryan, Fraiha, Lainson \& Shaw, 1986). According to original description, some paratypes of Bichromomyia olmeca nociva (Young \& Arias, 1982) and Psychodopygus yucumensis (Le Pont, Caillard, Tibayrenc \& Desjeux, 1986) should have been deposited in the Instituto Evandro Chagas collection, but not one of these has been found.

This study presents an annotated catalog of the type material of the Phlebotominae deposited at the ColFleb IEC to help entomologists searching for types.

\section{Material and methods}

Each type specimen was examined individually after checking the respective labels against original descriptions and additional bibliographical material. An active search 
for glass slides stored in boxes of nontype material was undertaken and the slides carefully analyzed to avoid excluding types which might have been mislaid.

After screening and comparison with original drawings, the type status of the specimens was confirmed and those identified were reorganized in horizontal slide cabinets with red labels for holotypes/"allotypes"; and green labels for paratypes/"syntypes". The list presents basic information directly from the original labels (species name, date, locality and collector/determinator). Although some types were originally classified using classical criteria (Lewis et al. 1977, Ready et al. 1980), this catalogue follows the phylogenetic classification proposed by Galati (1995). The article is presented in accordance with earlier lists of other insect groups (Zompro and Domenico 2005, Mello and Ziegler 2012, Reboleira et al. 2012). Image database and digitalization of information has been undertaken and the latter is available at Species Link Database (http://splink.cria.org.br).

The taxon and respective available data are listed below in alphabetical order of genus using the following format:

Binomial name Author, publication date.

Journal or Technical Bulletin, volume (number): pages.

Typology: Specimens' number and gender. Information for all specimens was a direct copy of the labels with no modification. Labels are indicated by quotation marks (" "), with each line in the label separated by a double slash (//), and handwriting information in labels indicated by italics.

Type-locality: locality or municipality (geographical coordinates), State or department, country.

Original name: as in the original description.

Additional note: only Brazilian institutions were assessed. Characteristics of each type series were highlighted giving the number of slides and number of specimens mounted on them, mentioning if the specimens were dissected or remounted or the presence of a label on the slide.

\section{Unusual abbreviations are listed below:}

Coll. collector

Coll. site collection site

Det. Determinator

Dept. department

Met. Method of capture

sp. n. new species

rem. remounted

SH. Shannon trap

Sp. $\quad$ species name 


\section{Results}

The following annotated catalogue to each type species deposited in the ColFleb IEC (splink.cria.org.br/) is given below.

\section{List of type material}

Nyssomyia richardwardi (Ready \& Fraiha, 1981)

Revista Brasileira de Biologia 41(4): 705-712.

Paratypes: 1 female "Wellcome // Parasitology Unit // Slide n 44.17 // Sp Lu. richardwardi // Det: Paratype // Coll. Site Km 43 // Altamira-Itaituba // Pará-Brasil // Met. Igarapé // Isca humana // Date 21/8/1971" [ColFleb IEC 149]; 1 female "Wellcome // Parasitology Unit // Slide 44.18 // Sp Lu. richardwardi // Det: Paratype // Coll. Site Km 43 // Altamira- Itaituba // Pará-Brasil // Met. Igarapé // Isca humana // Date 21/8/1971" [ColFleb IEC 150].

Type-locality: $\mathrm{km} 43$ of the Transamazonian Highway, between Itaituba $\left(04^{\circ} 16^{\prime} 33^{\prime \prime S} ; 55^{\circ} 59^{\prime} 02^{\prime \prime W}\right)$ and Altamira $\left(03^{\circ} 11^{\prime} 41^{\prime \prime S} ; 52^{\circ} 12^{\prime} 33^{\prime \prime} \mathrm{W}\right)$ municipalities, State of Pará, Brazil.

Original name: Lutzomyia richardwardi.

Additional note: two slides.

\section{Nyssomyia shawi (Fraiha, Ward \& Ready, 1981)}

Revista Brasileira de Biologia 41(4): 699-703.

Paratypes: 4 females "Wellcome // Parasitology Unit // Slide n 43. 'N'// Sp Lu. shawi // Det: Paratype // Coll. Site // Serra dos Carajás // Marabá, Pará // Met. Isca humana // Date 20/9/1974' [' $N$ '= slide n43.15, 43.25, 43.28, 43.29] [ColFleb IEC 159- 162]; 8 females "Wellcome // Parasitology Unit // Slide 43'N'// Sp Lu. shawi // Det: Paratype // Coll. Site // Serra dos Carajás // Marabá- Pará // Met. Isca humana // Date 22/9/1974" [' $N$ '= slide $n^{\circ} 43.09,43.14,43.16,43.17,43.23,43.24,43.26,43.27$ ] [ColFleb IEC 163-170]; 6 females "Wellcome // Parasitology Unit // Slide n43'N'// Sp Lu. shawi // Det: Paratype // Coll. Site // Serra dos Carajás // Marabá- Pará // Met. Isca humana // Date 23/9/1974' [' $N=$ slide n'43.02, 43.03, 43.04, 43.05, 43.07, 43.08] [ColFleb IEC178- 183]; 7 females "Wellcome // Parasitology Unit // Slide 43. 'N'// Sp Lu. shawi // Det: Paratype // Coll. Site // Serra dos Carajás // Marabá-Pará // Met. Isca humana // Date $9 / 1974$ " [ $N$ ' = slide n'43.01, 43.06, 43.12, 43.13, 43.18, 43.21, 43.22] [ColFleb IEC 171-177]; 9 males "Wellcome // Parasitology Unit // Slide n'43. 'N'// Sp Lu. shawi // Det: Paratype // (Serra dos carajás // Coll. Site Marabá- // Pará- Fevereiro 1975) // Met. Criado em lab. // Date Abril- Junho 1975 // R.D. Ward col." ['N'= slide n43.44, 43.45, 43.48, 43.49, 43.50, 43.51, 43.53, 43.61, 43.62] [ColFleb IEC 184-192]. 
Type-locality: Serra dos Carajás (0606'29"S; 50¹8'36"W), Marabá municipality, state of the Pará, Brazil.

Original name: Lutzomyia shawi.

Additional note: 34 slides.

Nyssomyia umbratilis (Ward \& Fraiha, 1977)

Journal of Medical Entomology 14(3): 313-317.

Holotype: female "Wellcome // Parasitology Unit // Lu. umbratilis // Slide ${ }^{\circ}$ Holótipo // Sp 260.65 // Det." [ColFleb IEC 145].

Paratype: 1 female "Wellcome // Parasitology Unit // Coll. Site Area 2'// Lu umbratilis // Jari // Met. Tree trunks // Date 19/7/76// Lu. umbratilis" [ColFleb IEC 146].

Type-locality: Monte Dourado $\left(00^{\circ} 53^{\prime} 23^{\prime \prime S}\right.$; 52 $\left.36^{\circ} 08^{\prime \prime W}\right)$, locality, Almeirim municipality, state of Pará, Brazil.

Original name: Lutzomyia (Nyssomyia) umbratilis.

Additional note: The two females mounted on the same glass slide. The locality of Jari actually refers to Monte Dourado, in Almeirim municipality, State of Pará.

\section{Nyssomyia yuilli yuilli (Young \& Porter, 1972)}

Journal of Medical Entomology 9(6): 524-526.

Paratypes: 1 male "Colombia \#179//Antioquia dept., // 24Km south and // 21 Km west of / Zaragoza. // in light trap // 3 may 1970 // coll: C.M. Porter // D L503-D1202-1 // Lutzomyia // yuilli // Young // Porter // Paratype // Det: D. G. Young" [ColFleb IEC 157]; 1 female "Colombia // Antioquia dept., // $24 \mathrm{Km}$ south and // $21 \mathrm{Km}$ west of // Zaragoza. // in light trap // 3 may 1970 // coll: C.M. Porter // D L503-D1202-1 // Lutzomyia // yuilli // Young // Porter // Paratype // Det: D.G. Young" [ColFleb IEC 156].

Type-locality: Zaragoza $\left(07^{\circ} 29^{\prime} 23^{\prime \prime N}\right.$; 74 $\left.4^{\circ} 52^{\prime} 03^{\prime \prime W}\right)$, Antioquia Department, Colombia.

Original name: Lutzomyia yuilli.

Additional note: two slides.

\section{Pintomyia gruta (Ryan, 1986)}

Flebótomos do Estado do Pará, Brasil (Diptera, Psychodidae, Phlebotominae). Documento Técnico. $\mathrm{n}^{\circ} 1$, Instituto Evandro Chagas, Belém, Pará, 154 p.

Paratypes: 1 male "Wellcome o // Parasitology Unit // Slide n Paratipo // Sp Lu. gruta // Det: Lee Ryan // Coll. Site Gruta // Carajás NI // Met. CDC // Date: 28/3/1985" [ColFleb IEC 139]; 1 male "Wellcome ô // Parasitology Unit // Paratipo // Slide n // Sp Lu. gruta // Det: Lee Ryan // Coll. Site Gruta // Carajás NI // Met. CDC // Date: 
28.3.85" [ColFleb IEC 140]; 1 male "Wellcome $\widehat{~} / /$ Parasitology Unit // Paratipo // Slide n'// Sp Lu. gruta // Det: Lee Ryan // Coll. Site Gruta // Carajás NI // Met. CDC // Date: 28.3.85" [ColFleb IEC 142]; 1 female "Wellcome $q$ // Parasitology Unit // Paratipo // Slide n'// Sp Lu. gruta // Det: Lee Ryan // Coll. Site Carajás // NI Gruta no. $2 / /$ Met. CDC // Date: 14/3/86" [ColFleb IEC 141]; 1 female "diss Wellcome 9 // Parasitology Unit //Slide nParatipo // Sp Lu. gruta // Det: Lee Ryan // Coll. Site Carajás // NI Gruta // Met. CDC // Date: 10/2/1985" [ColFleb IEC 138].

Type-locality: Serra dos Carajás (06 06'29"S; 50¹8'36"W), Marabá municipality, state of the Pará, Brazil.

Original name: Lutzomyia gruta.

Additional note: five slides. The term "diss" in the beginning of the label ColFleb IEC 183 refers to dissected specimens.

\section{Psychodopygus lainsoni Fraiha \& Ward, 1974}

Bulletin of Entomological Research 64: 209-212.

Syntypes: 1 male "Psychodopygus // lainsoni sp. n. // Sintipo Ô-Km 46 // AltamiraItaituba // Rod. Transamazônica // Pará-Brasil Km 46 Altamira- Itaituba Rod. Transamazônica, Pará, Brasil // Criado em laboratório // Ps. lainsoni ô" [ColFleb IEC 131]; 1 male "Psychodopygus // lainsoni sp. n. // Sintipo Ô-Km 46 // Altamira- Itaituba // Rod. Transamazônica // Pará-Brasil Km 46 Altamira-Itaituba Rod. Transamazônica, Estado do Pará // Criado em laboratório" [ColFleb IEC 132].

Type-locality: $\mathrm{km} 46$ of the Transamazonian Highway, between Itaituba $\left(04^{\circ} 16^{\prime} 33^{\prime \prime S}\right.$; 55 $\left.59^{\prime} 02^{\prime \prime W}\right)$ and Altamira $\left(03^{\circ} 11^{\prime} 41^{\prime \prime S}\right.$; 52 $\left.2^{\circ} 12^{\prime} 33^{\prime \prime W}\right)$ municipalities, state of the Pará, Brazil.

Original name: Psychodopygus lainsoni

Additional note: one slide with two specimens. No label. Data written directly on the slide with white brush.

\section{Psychodopygus leonidasdeanei Fraiha, Ryan, Ward, Lainson \& Shaw, 1986}

Memórias do Instituto Oswaldo Cruz 81(3): 333-339.

Holotype: male "Wellcome // Parasitology Unit // Slide no? // Sp Lu. leonidasdeanei // Det: Lee Ryan // Coll. Site Santarém // Serra do BEC // Met: SH (2) // 20/7/1984 // 18-19hs" [ColFleb IEC 121].

Paratypes: 1 female "Wellcome // Parasitology Unit // Slide n // Sp Lu leonidas // Det deanei // Transamazônica // Coll. Site Km 112 // Itaituba-Altamira // Met: isca humana // 18:19hs // Date 30/11/71" [ColFleb IEC 130]; 42 females "Wellcome // Parasitology Unit // Lu leonidasdeanei // Slide n\%// Sp // Det // Coll. Site Km 112 // Itaituba-Altamira // Met: Isca humana // Date 3-4-75 // Fraiha \& Ward col." [ColFleb 
IEC 1-6, 27, 31-33, 37, 39-42, 48, 50, 52, 53, 55, 56, 60-62, 64, 65, 67, 69-72, 77, 83, 97, 101, 102, 104, 106, 107, 117, 118, 120]; 1 female "Wellcome // Parasitology Unit // Lu leonidasdeanei // Slide n\%// Sp // Det // Vicinal 11/13 Km 46 // Coll. Site Altamira // Itaituba- Lote 39 // Met: Isca humana // Date 18.12.73 // Fraiha col." [ColFleb IEC 11]; 2 females "Wellcome // Parasitology Unit // Slide n ${ }^{\circ} p$. grp. // Sp Lu. leonidasdeanei // Det Lee ryan // Coll. Site Santarém // Serra do BEC // Met SH (2) 18-19hs // date 10.7.1984 [ColFleb IEC 122 (allotype), 123].

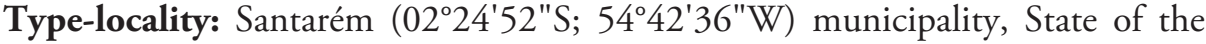
Pará, Brazil.

Original name: Psychodopygus leonidasdeanei

Additional note: To the male holotype the sentence "met: SH (2)" refers to Shannon trap with two collectors.

\section{Psychodopygus llanosmartinsi Fraiha \& Ward, 1980}

Revista da Fundação de Serviços de Saúde Pública 25(1): 10-14.

Paratypes: 1 female "Loc Pilcopata // Dep. Cuzco // Estado // Peru // Cap por J.E. // Silva // Em 21/6/73 // Lam n²46.293 // NE n 1905/73 // Esp L. amazo // nensis // Det. A.V. Martins // Em Set. 1973. [ColFleb IEC 158]; 1 female. "Loc Pilcopata // Dep. Cuzco // Estado // Peru // Cap por J.E. // Silva // Em 21/6/73 // Lam n 46.297 // NE n¹905/73 // Esp L. amazo // nensis // Det. A.V. Martin // Em Set. 1973" [ColFleb IEC 159].

Type-locality: Pilcopata $\left(02^{\circ} 30^{\prime} 00^{\prime \prime S} ; 78^{\circ} 55^{\prime} 00^{\prime \prime W}\right)$, Cuzco Department, Peru.

Original name: Psychodopygus llanosmartinsi.

Additional note: two slides. The original label refers to the specimens as Lutzomyia amazonensis.

\section{Psychodopygus wellcomei Fraiha, Shaw \& Lainson, 1971}

Memórias do Instituto Oswaldo Cruz 69(3): 489-500.

Syntypes: 1 female "Psychodopygus // wellcomei // Fraiha, Shaw \& lain- // son, 1971, Sintipo 9 // Serra Norte, Area 2 // Serra dos Carajás // Marabá, Pará, BR // Isca Humana // Área de cerrado // na borda da mata // 23. Nov. 1968 [ColFleb IEC 133]; 1 male "P. wellcomei // Fraiha, Shaw // \& Lainson, 1971 // (capt. em armad. // Disney c/ cobaio // Psychodopygus // wellcomei // Sintipo ô // Serra Norte-A1 // Serra dos Carajás // Marabá, Pará, BR // 23-24/XI/1968" [ColFleb IEC 134].

Type-locality: Serra dos Carajás (06 06'29"S; 50¹8'36"W), Marabá municipality, State of the Pará, Brazil.

Original name: Psychodopygus wellcomei.

Additional note: two slides. 
Trichophoromyia adelsonsouzai Santos, Silva, Barata, Andrade \& Galati, 2014 Memórias do Instituto Oswaldo Cruz 109: 2014 (ahead of print).

Holotype: male "Universidade de São Paulo // Faculdade de Saúde Pública // Epidemiologia // BRASIL - Pará // Vitória do Xingu entre Altamira e // Anapu (km 27 da R. Transamzônica) // Armadilhas CDC e Shannon // Cols. Santos TV \& Silva FMM, // 04-15/II/2012 a 10-26/VVI/2012 // Trichophoromyia adelsonsouzai // Santos, Silva, Barata, Andrade \& // Galati 2013/ Holótipo §̊ [Colfleb IEC 184].

Paratypes: 13 males "Universidade de Sáo Paulo // Faculdade de Saúde Pública // Epidemiologia // BRASIL - Pará // Vitória do Xingu entre Altamira e // Anapu (km 27 da R. Transamzônica) // Armadilhas CDC e Shannon // Cols. Santos TV \& Silva FMM, // 04-15/II/2012 a 10-26/VVI/2012 // Trichophoromyia adelsonsouzai // Santos, Silva, Barata, Andrade \& // Galati 2013 [ColFleb IEC 185-194]; 5 females "Universidade de São Paulo // Faculdade de Saúde Pública // Epidemiologia // BRASIL - Pará // Vitória do Xingu entre Altamira e // Anapu (km 23 da R. Transamzônica) // Armadilhas CDC e Shannon // Cols. Santos TV \& Silva FMM, // 04-15/II/2012 a 10-26/VVI/2012 // Trichophoromyia adelsonsouzai // Santos, Silva, Barata, Andrade \& // Galati 2013 [ColFleb IEC 195-199].

Type-locality: km 47 of the Transamazonian Highway, between Altamira $\left(03^{\circ} 11^{\prime} 41^{\prime \prime S} ; 52^{\circ} 12^{\prime} 33^{\prime \prime W}\right)$ and Anapu (03⒉ $21^{\prime \prime S}$; 51 $\left.1^{\circ} 11^{\prime} 55^{\prime \prime W}\right)$ municipalities, State of the Pará, Brazil.

Original name: Trichophoromyia adelsonsouzai.

Additional note: 19 slides.

\section{Thichophoromyia brachipyga (Mangabeira, 1942)}

Memórias do Instituto Oswaldo Cruz 37(2): 111-218.

Paratype: 1 male "170 // Inst. Osw. Cruz // No. Paratypo // F. brachipygus // Mangabeira, 1942 // Piratuba, M. Aba- // eté (Pará) em bura- // co de tatu-VIII- 940 // Mang. coll." [ColFleb IEC 148].

Type-locality: Abaetetuba $\left(01^{\circ} 43^{\prime} 04^{\prime \prime} \mathrm{S}\right.$; $\left.48^{\circ} 52^{\prime} 58^{\prime \prime W}\right)$ municipality, State of the Pará, Brazil.

Original name: Flebotomus brachipygus.

Additional note: one slide. The municipality of Abaeté actually refers to Abaetetuba.

\section{Thrichophoromyia readyi (Ryan, 1986)}

Flebótomos do Estado do Pará, Brasil (Diptera, Psychodidae, Phlebotominae), Documento técnico nº 1 , Instituto Evandro Chagas, Belém, Pará, 154 p.

Holotype: 1 male "holotype Wellcome // Parasitology Unit // remounted 1.11.85 // Slide $n^{\circ}$ L. Ryan // Sp Lu. ready // Det: R. D. Ward // Transamazônica // Coll. Site Km 
25 // Itaituba-Altamira // Met. toca tatu // Date 29/11/71 // coll R.D.W." [ColFleb IEC 142].

Paratypes: 1 female "Wellcome // Parasitology Unit // allotype // Slide n R.D. Ward collect // Sp Lu. ready // Det: Lee Ryan // Transamazon // Coll. Site Km 25 // Itaituba-Altamira // Met. CDC// Date 2.12.71" [ColFleb IEC 143 (allotype)]; 1 male "Wellcome // Parasitology Unit // R.D.Ward // Slide n³40.61 // Sp Lu. ready // Det: Lee Ryan // Transamazon // Coll. Site Km 25 // Itaituba-Altamira // Met. Armadillo burrow // Date 29.11.1971 // rem. 10.2.1986" [ColFleb IEC 145].

Type-locality: $\mathrm{km} 25$ of the Transamazonian Highway, between Itaituba

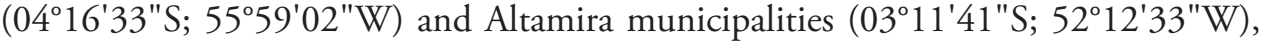
State of the Pará, Brazil.

Original name: Lutzomyia readyi.

Additional note: three slides. Paratype [ColFleb IEC 145] was remounted on 10/ II/1986 and the holotype on 1/XI/1985.

\section{Conclusion}

Until now, there are 12 sand fly species included as type specimens deposited in the COLFleb IEC. The type material of Ev. carmelinoi, including male holotype and the female described as allotype (= paratype), is lost. The other two species mentioned in the original description as deposited in the "Instituto Evandro Chagas", Bi. olmeca nociva and Ps. yucumensis were not found in the collection. According to original description the species described by Mangabeira during 1938 and 1942 were deposited in the "Instituto Oswaldo Cruz" and those by Damasceno and collaborators and between 1944 and 1950 in the Natural History Museum of the United States (Smithsonian Museum, Washington D.C.).

The ColFleb IEC is the only Institute in Brazil that holds type-species of Pi. gruta, Ps. leonidasdeanei and Th. readyi (AJA, personal observation). The male holotype and 2 male and three female paratypes of Ps. lainsoni are deposited at the "Coleção Padrão" of the "Departamento de Epidemiologia" of the "Faculdade de Saúde Pública" of the "Universidade de São Paulo" (FSP-USP). Three other type series of sand flies can be found in the same Institution: two female paratypes of $N y$. umbratilis and a male and a female "topotypes" of Ny. yuilli yuilli. In the "Coleção de Flebotomíneos" of the "Centro de Pesquisas René Rachou" (FIOCRUZ-COLFLEB) another slide of a Ps. llanosmartinsi male, described as "plesiotype/paratype", was found in addition to two paratype males ( $\left.\mathrm{n}^{\circ} 44.38-44.39\right)$ and six paratype females $\left(\mathrm{n}^{\circ} 44.20-44.25\right)$ of $N y$. richardwardi, and four paratype males ( $\left.\mathrm{n}^{\circ} 43.52,43.54,43.55,43.56\right)$ and six paratype female ( ${ }^{\circ} 43.30-43.35$ ) of $N y$. shawi. With regards to Ps. wellcomei, one slide of a syntype female is deposited in the FIOCRUZ-COLFLEB, and one syntype male and two syntype females of the same species are found in the entomological collection named "Costa Lima" in the Instituto Oswaldo Cruz (CEIOC). According to Fraiha and Ryan (1986) more than 20 valid species were described by Dr. Octavio Mangabeira Filho. 
Unfortunately, few specimens described by him have been found in Brazilian institutions (Andrey Andrade, personal communication). Of these, just one male paratype of Trichophoromyia brachipyga was located in the ColFleb IEC and another male paratype is deposited in the "John Lane Collection" of the FSP-USP. Finally, paratypes of Th. adelsonsouzai have been distributed to different collections in Brazil (Santos et al. 2014).

Depository institutions and natural history collections are very important to know and document biodiversity around the world. Unfortunately, these holdings of biodiversity information are often not easy to survey and it is common to observe that some type species are not deposited according to the original description. This may be due to the fact that the author does not always send them to the intended institution, or the specimens are later donated or sold to other institutions, or sadly they were destroyed or lost. Annotated catalogues are the first step to organize these invaluable collections and they may help in updating the deposited material. The authors hope that similar studies can be made by other institutions which have relevant collections, particularly those that hold type-species of Brazilian species.

\section{Acknowledgments}

The authors wish to thank: the previous entomology team RD Ward, PD Ready, L Ryan, H Fraiha, AAA Souza (in memoriam) and the prozoologists R Lainson and JJ Shaw for the great efforts dedicated to founding and organizing this collection; MGS Silva (in memoriam) for her curatorial care; the Coordenação de Aperfeiçoamento de Pessoal de Nivel Superior (CAPES) for the financial support given to the TVS, and the Fundação de Amparo à Pesquisa do Estado de São Paulo (FAPESP) for the financial support given to AJA (process number 2010/15802-7). The authors are also indebted to R Lainson for his careful revision of the English text.

\section{References}

Andrade AJ, Shimabukuro PHF, Galati EAB (2013) On the taxonomic status of Phlebotomus breviductus Barretto, 1950 (Diptera: Psychodidae: Phlebotominae). Zootaxa 3734: 477-484. doi: 10.11646/zootaxa.3734.4.5

Fraiha H, Ryan L (1986) Taxonomia de flebotomíneos (Diptera: Psychodidae) In: Fundaçáo Serviços de Saúde Pública. Instituto Evandro Chagas: 50 anos de contribuição às ciências biológicas e à medicina tropical. s.l. Fundação Serviços de Saúde Pública, 295-306.

Galati EAB (1995) Phylogenetic systematics of Phlebotominae (Diptera, Psychodidae) with emphasis on American groups. Boletín de la Direction de Malariologia y Saneamento Ambiental 35: 133-142.

Galati EAB (2003) Morfologia, terminologia de adultos e identificação dos táxons da América. In: Rangel EF, Lainson R (Eds) Flebotomíneos do Brasil, Fiocruz, Rio de Janeiro, 53-175. 
Lainson R, Shaw JJ (2005) New world leishmaniasis. In: Cox FEG, Wakelin D, Gillespie SM, Despommier DD (Eds) Topley and Wilson's Microbiology and Microbial Infections (Parasitology). 10 $0^{\text {th }}$ edition. Hodder Arnold Press. 338 Euston Road, London NWI, 313-349.

Lewis DJ, Young DG, Fairchild GB (1977) Proposals for a stable classification of the Phlebotomine sandflies (Diptera: Psychodidae). Systematic Entomology 2: 319-332. doi: 10.1111/ j.1365-3113.1977.tb00381.x

NPS Museum Handbook (2005) Apendix T: Curatorial care of biological collections. Part 1: 1-138. link: http://www.nps.gov/museum/publications/MHI/AppendixT.pdf

Mello RL, Ziegler J (2012) Catalogue of the type material of Neriidae (Diptera, Schizophora) in the collection of the Museum für Naturkunde Berlin, Germany. Deutsche Entomologische Zeitschrift 59: 147-163.

Ready PD (2013) Biology of phlebotomine sand flies as vectors of disease agents. Annual Review of Entomology 58: 227-250. doi: 10.1146/annurev-ento-120811-153557

Ready PD, Fraiha H, Lainson R, Shaw JJ (1980) Psychodopygus as a genus: Reasons for a flexible classification of the Phlebotomine sand flies (Diptera: Psychodidae) Journal of Medical Entomology 17: 75-88.

Reboleira ASPS, Pérez AJ, López H, Macías Hernández N, de la Cruz S, Oromí P (2012) Catalogue of the type material in the entomological collection of the University of La Laguna (Canary Islands, Spain). I. Arachnida. Zootaxa 3556: 61-79. urn:lsid:zoobank. org:pub:7E93D346-F3B1-4DF1-A699-9C49212DDB1C

Santos SO, Arias J, Ribeiro AA, Hoffmann MP, Freitas RA, Malacco MAF (1998) Incrimination of Lutzomyia cruzi as a vector of American Visceral Leishmaniasis. Medical ADN Veterinary Entomology 12: 315-317. doi: 10.1046/j.1365-2915.1998.00104.x

Santos TV, Silva FMM, Barata IR, Andrade AJ, Galati EAB (2014) A new species of phlebotomine, Trichophoromyia adelsonsouzai (Diptera: Psychodidae) of Brazilian Amazonia. Memórias do Instituto Oswaldo Cruz 109: ahead of print. doi: 10.1590/0074-0276130159 Savani ES, Nunes VL, Galati EA, Castilho TM, Zampieri RA, Floeter-Winter LM (2009) The finding of Lutzomyia almerioi and Lutzomyia longipalpis naturally infected by Leishmania spp. in a cutaneous and canine leishmaniasis focus in Serra da Bodoquena, Brazil. Veterinary Parasitology 160: 18-24. doi: 10.1016/j.vetpar.2008.10.090

Suarez AV, Tsutsui ND (2004) The Value of Museum Collections for Research and Society. BioScience 54: 66-74. doi: 10.1641/0006-3568(2004)054[0066:TVOMCF]2.0.CO;2

Zompro O, Domenico FC (2005) Catalogue of the type material of Phasmatodea (Insecta) deposited in Brazilian Museums. Iheringia, Série Zoologia 95: 255-259. doi: 10.1590/ S0073-47212005000300005 